\title{
Secretion from umbilicus
}

\author{
Tetsu Sakamoto, Hiroshi Takase, ${ }^{\circledR}$ Taro Shimizu
}

Department of Diagnostic and Generalist Medicine, Dokkyo Medical University Hospital, Shimotsuga-gun, Japan

\section{Correspondence to} Dr Taro Shimizu, shimizutaro7@gmail.com

Accepted 27 July 2019

\section{DESCRIPTION}

A 24-year-old woman without significant medical history presented with a 5-day history of lower abdominal discomfort and purulent secretion from her umbilicus. She was well until 5 days prior when she noticed periumbilical abdominal pain. She denied fever, nausea, diarrhoea and melaena.

Abdominal examination showed mild distension below her periumbilical area and purulent discharge from her umbilicus (figure 1A). There was a pus-filled pocket of $4 \mathrm{~cm}$ depth with an opening at the umbilicus (figure 1B). Gram staining of the pus showed polymicrobial organisms. Abdominal CT scan with contrast revealed periumbilical abscess, which was consistent with the complication of the urachal remnant (figure 2).

The abscess was successfully treated with 10-days oral amoxicillin-clavulanate. Corynebacterium spp was isolated from the culture. Three months later, laparoscopic radical excision of the urachal remnant was performed without postoperative complications.

The incidence of urachal anomalies is reported to be approximately 1 in 5000 population in adults. ${ }^{1}$

Most common complications of the urachal remnant are an infection and malignant degeneration. The incidence of infection is unclear. Malignant degeneration is $<1 \%$ of all bladder cancer. ${ }^{1}$ The typical presentations of infection are abdominal pain, dysuria, and umbilical drainage. ${ }^{1-3}$ The usually isolated organisms are Staphylococcus spp, Enterococcus faecalis, Escherichia coli and Proteus mirabilis. ${ }^{1-3}$ Because of the variety of causative organisms, broad-spectrum antibiotics should be used, as in this case. Ultrasonography is useful as the initial test, followed by CT. ${ }^{13}$ Recommendations suggest all urachal remnants should be excised to avoid complications after the resolution of current inflammation. $^{13}$

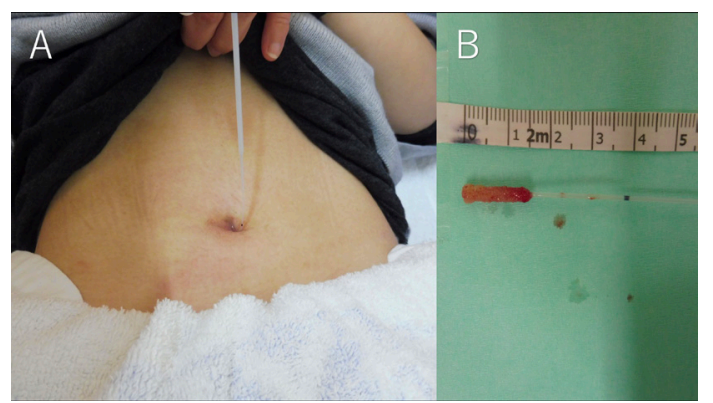

Figure 1 Secretion from umbilical pocket $(A)$, which was about $4 \mathrm{~cm}$ in depth (B).

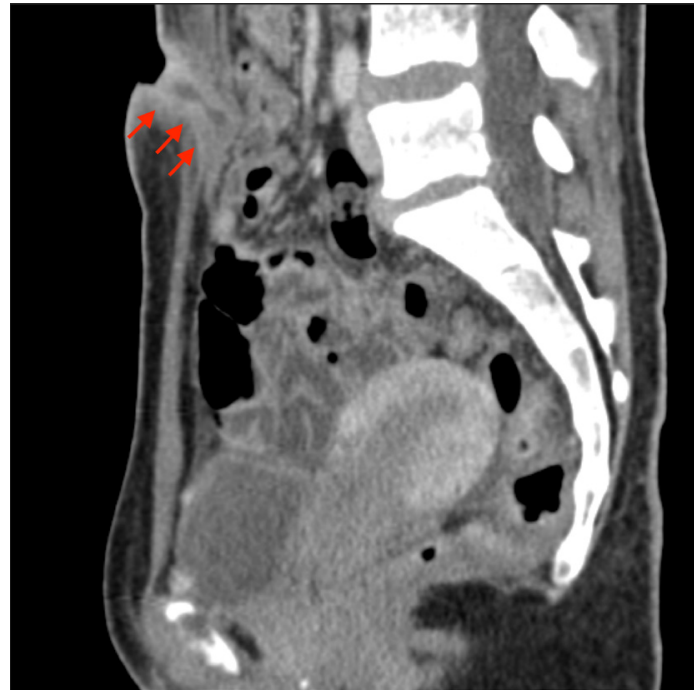

Figure 2 Sagittal abdominal CT scan with contrast revealing urachal remnant (arrow).

\section{Patient's perspective}

I am glad to be diagnosed and get treatment.

\section{Learning points}

- Think complication of the urachal remnant when you see purulent secretion from the umbilicus.

- All urachal remnants should be excised to avoid infection and malignant degeneration.

Contributors TSa: provided medical care with HT. TSa: wrote the initial draft of the manuscript. HT and TSh: contributed to assist in the preparation of the manuscript. All authors approved the final version of the manuscript.

Funding The authors have not declared a specific grant for this research from any funding agency in the public, commercial or not-for-profit sectors.

Competing interests None declared.

Patient consent for publication Obtained.

Provenance and peer review Not commissioned; externally peer reviewed.

\section{REFERENCES}

1 Parada Villavicencio C, Adam SZ, Nikolaidis P, et al. Imaging of the Urachus: Anomalies, Complications, and Mimics. Radiographics 2016;36:2049-63.

2 Ashley RA, Inman BA, Routh JC, et al. Urachal anomalies: a longitudinal study of urachal remnants in children and adults. J Urol 2007; 178(4 Pt 2):1615-8.

3 Tazi F, Ahsaini M, Khalouk A, et al. Abscess of urachal remnants presenting with acute abdomen: a case series. J Med Case Rep $2012 ; 6: 226$ 
Copyright 2019 BMJ Publishing Group. All rights reserved. For permission to reuse any of this content visit https://www.bmj.com/company/products-services/rights-and-licensing/permissions/

BMJ Case Report Fellows may re-use this article for personal use and teaching without any further permission.

Become a Fellow of BMJ Case Reports today and you can:

- Submit as many cases as you like

- Enjoy fast sympathetic peer review and rapid publication of accepted articles

Access all the published articles

Re-use any of the published material for personal use and teaching without further permission

Customer Service

If you have any further queries about your subscription, please contact our customer services team on +44 (0) 2071111105 or via email at support@bmj.com.

Visit casereports.bmj.com for more articles like this and to become a Fellow 